\title{
How about selling commodity futures losers?
}

\author{
Jangkoo Kang ${ }^{\dagger}$ and Kyung Yoon Kwon*
}

\begin{abstract}
This paper explores the benefits of extending the investment universe to commodity futures, from the perspective of momentum traders. We find that the growth-optimal portfolio includes negative (positive) weights on commodity futures losers (stock winners). Motivated by this finding, we construct a joint momentum strategy, buying stock winners and selling commodity futures losers, and show that it generates an average monthly return of up to $1.91 \%$ and provides much lower skewness $(0.04)$ and kurtosis (1.27) than a traditional stock momentum strategy. It also greatly improves profitability, especially in unfavorable market states, and thus effectively manages tail risk.
\end{abstract}

JEL classification: G10; G11; G12

Keywords: Momentum; Commodity futures; Market anomalies; Momentum crashes; Tail risk

$\dagger$ College of Business, Korea Advanced Institute of Science and Technology; 85 Hoegiro, Dongdaemoon-gu, Seoul, 02455, South Korea; e-mail jkkang@kaist.ac.kr.

* Corresponding author. Department of Accounting and Finance, Strathclyde Business School, University of Strathclyde, 199 Cathedral street, Glasgow G4 0QU, UK; tel. +44-141-548-3935; e-mail arari1115@gmail.com.

The data that support the findings of this study are available from the corresponding author upon reasonable request.

Acknowledgements: This work was supported by the Ministry of Education of the Republic of Korea and the National Research Foundation of Korea (NRF-2017S1A5B5A07064108) 


\section{Introduction}

Momentum is one of the most studied phenomena in the asset pricing literature. Momentum indicates that assets with recent outperformance (underperformance) relative to others tend to continuously outperform (underperform) in the future. The stock momentum strategy, which buys recent stock winners and sells recent stock losers, has been shown to be attractive, generating positive and significant returns, on average. On the other hand, this strategy exhibits great negative skewness and high kurtosis. Recent empirical studies have reported that the stock momentum strategy occasionally generates large negative returns that are especially notable in bear markets or during market rebounds (Grundy and Martin, 2001; Daniel et al., 2012; Barroso and Santa-Clara, 2015; Daniel and Moskowitz, 2016). Specifically, Barroso and Santa-Clara (2015) report that the stock momentum strategy delivered a return of $-91.59 \%$ over two months in 1932 and a return of $-73.42 \%$ over three months in 2009 , both when the stock market was rebounding from a severe recession.

Momentum profit was first documented in the US stock market by Jegadeesh and Titman (1993); however, the literature has since accumulated evidence of the momentum phenomenon in other markets, including the commodity futures market (Erb and Harvey, 2006; Miffre and Rallis, 2007; Asness et al., 2013; Kang and Kwon, 2017; Lutzenberger et al., 2017). In this paper, we examine a momentum strategy in the investment universe consisting of the commodity futures markets as well as the stock market. Investments in commodity futures markets have increased rapidly over the last few years. ${ }^{1}$ Commodity

\footnotetext{
${ }^{1}$ According to index investment data provided by the US Commodity Futures Trading Commission, the total value of index investments in the US commodity futures market was about $\$ 119$ billion at the end of 2008 but grew to about $\$ 187$ billion by the end of 2014 . At the end of 2010, when the financial markets were affected by the global financial crisis, the total value of index investments in the US commodity futures market was especially high, at \$293 billion.
} 
futures are one of the most important hedge instruments and are also useful in enhancing diversification benefits in the asset universe due to their relatively low correlation with other assets. The academic literature has extensively investigated hedging effects and the diversification benefits of commodity futures (Conover et al., 2010; Daskalaki and Skiadopoulos, 2011; Belousova and Dorfleitner, 2012), but the benefits of extending the investment universe to commodity futures from the perspective of momentum traders have not yet been explored. We expect momentum profits using commodity futures and stocks together to remain significantly positive but with less risk, because commodity futures momentum returns have a very low correlation with stock momentum returns. Kang and Kwon (2017) document a significant positive relation between the two momentums, using international commodity futures market data, but report that this correlation is quite low and that the commodity futures momentum cannot be fully explained by the stock momentum. Our results also show that the correlation between the stock momentum and the commodity futures momentum ranges from -0.035 to 0.037 , which is quite low. This low correlation cannot be obtained in the case of a momentum strategy in the other markets. Specifically, during our sample period, we find that our stock-only momentum has correlations of $0.35,0.15$, and 0.24 , respectively, with the equity index, currency, and fixed income momentums constructed by Asness et al. (2013). ${ }^{2}$

This paper examines how we can improve the performance of the stock market momentum strategy by combining it with the commodity futures momentum strategy in terms of risk-adjusted returns, utility gains, and alleviating tail risk. Using a data set from January 1979 to June 2015, we first investigate a way to combine the two momentums by estimating the growth-optimal portfolio. One way to expand the investment universe into commodity futures in addition to the stock market from the momentum strategy is to create a momentum strategy that treats all assets as one asset class and selecting the winners and loser among all the assets. However, commodity futures are regarded as a distinctive asset class compared to

\footnotetext{
${ }^{2}$ See https://www.aqr.com/Insights/Datasets.
} 
stocks having different nature and also different return distributions. Thus, treating them as one asset class would not be an appropriate approach. Thus, we take into consideration only the combinations of the stock winner portfolio, the stock loser portfolio, the commodity futures winner portfolio, and the commodity futures loser portfolio. It is rare in the literature for a momentum strategy to be constructed across markets, such as the stock market and the commodity futures market. Though Asness et al. (2013) examine the profitability of momentum strategies in diverse asset universes, they do not try to construct a cross-market momentum strategy that outperforms single-market momentum strategies.

As a guide to construct a "better" momentum strategy, we examine the growth-optimal momentum strategy that is a combination of the four stock market and commodity futures market winners and losers and other stock portfolios, such as size, value, profitability, and investment portfolios. Because the growthoptimal portfolio is the optimal portfolio for investors with a log-utility function, it is the optimal portfolio for at least some investors. Our empirical estimates show that i) both stock losers and winners have large positive weights but stock winners carry a much larger positive weight than stock losers in the growthoptimal portfolio, ii) commodity futures winners have a positive weight but a much smaller weight than stock winners, and iii) commodity futures losers have a negative weight in the growth-optimal portfolio. The growth-optimal portfolio shows that a larger weight for winners than for losers in a single market, such as only the stock market or only the commodity futures market, is optimal, justifying the single-market momentum strategies. However, the results suggest another and probably stronger momentum strategy consisting of a long position in stock winners and a short position in commodity futures losers. This is the momentum strategy that we examine in detail in this paper.

Selling commodity futures losers has its advantages. First, commodity futures losers have much lower skewness and kurtosis relative to stock losers, which results in the lower tail risk of the commodity futures momentum strategy. For example, Daniel and Moskowitz (2016) report that the skewness values of the momentum returns in global equity markets, fixed income markets, and foreign exchange markets are -0.34 , 
-0.24 , and -0.54 , respectively, but commodity futures momentum returns have a skewness of only 0.01 (See Table 11 in Daniel and Moskowitz, 2016). Our results also show that short-term commodity futures momentum returns have a skewness of 0.160 and a kurtosis ${ }^{3}$ of 0.571 . This favorable feature of the return distribution of the commodity futures momentum is known in the literature but has not attracted much attention. Daniel and Moskowitz (2016) document that the stock momentum strategy is exposed to crash risk and stock momentum crashes are attributable to the short side of the momentum strategy, that is, stock losers. Thus, we expect that the substitution of commodity futures losers in the place of stock losers alleviates the tail risk of the traditional stock momentum strategy.

Moreover, selling commodity futures is more attractive than selling stocks, from the viewpoint of investors. Selling commodity futures is a more implementable strategy than selling stocks. Commodity futures offer leverage and are not subject to short-selling restrictions, unlike stocks. In stock markets, short sellers are charged a loan fee for the loan of the security and such loan fees are sometimes prohibitively expensive (D'Avolio, 2012). In addition, short sellers in the stock market are exposed to the short-selling risk of stock loans being recalled and loan fees increasing (Engleberg et al., 2018). Furthermore, short-sale restrictions, such as the uptick rule, can make short selling difficult or even impossible to implement. This difference in short-sale costs and short-sale restrictions between stocks and commodity futures is important from the perspective of investors (Lesmond et al., 2004; Stambaugh et al. 2012). Our joint momentum strategy, which buys stock winners and sells commodity futures losers, is free from this issue. In addition, since we use the prices of the nearest contracts that are liquid, selling commodity futures rather than selling stocks is much easier to implement and entails lower costs. Barroso and Santa-Clara (2015) note an ongoing debate about whether the plain (original stock) momentum strategy is economically exploitable after transaction costs. Daniel and Moskowitz (2016) document that their dynamic momentum strategy dramatically improves performance relative to traditional and other modified momentum strategies, but

\footnotetext{
${ }^{3}$ In this paper, kurtosis indicates excess kurtosis, and so the normal distribution has a value of 0.
} 
they also document that the actual implementation of their modified strategy would be accompanied by higher transaction costs. Our joint momentum strategy is expected to incur even lower transaction costs than the traditional stock momentum strategy, since selling in the commodity futures markets is less costly (especially in terms of transaction costs) and more easily implementable.

After finding that the joint momentum strategy is a strong candidate for a better momentum strategy that is more desirable from log-utility investors and could curtail tail risk and implementation costs, we examine its performance. First, we examine the properties of the return distribution of the joint momentum strategy. Our joint momentum strategies show a dramatic reduction in skewness and kurtosis. The skewness of the stock-only momentum strategy is -3.101 and its kurtosis is 21.872 , whereas the skewness of the joint momentum is -0.081 and its kurtosis is 2.113 (for the case of combining the 12-month stock winner and the 12-month commodity futures loser). Moreover, our joint momentum strategy produces higher profitability than the single-market momentum strategies in terms of the average return and the Sharpe ratio. The joint momentum strategies appear to have an average monthly return of up to $1.91 \%$ and an annualized Sharpe ratio of 0.82 , values that are much higher than those of the representative stock or bond indexes, such as the Standard \& Poor's (S\&P) 500 and Russell 2000, as well as those of the traditional stock momentum strategy or the commodity futures momentum strategy. ${ }^{4}$

Second, we investigate the time-varying performance of the strategy according to market states. We find that our joint strategy greatly improves profitability in recession and low-sentiment periods relative to the single-market momentum strategies. The performance of the stock momentum strategy is known to

\footnotetext{
${ }^{4}$ For example, Asness et al. (2013) investigate the existence of momentum effects in various asset universes and report that the Sharpe ratio of the momentum portfolio constructed within global non-stock asset classes is 0.63 , whereas the Sharpe ratio of our joint momentum strategies, buying the stock winner and selling the commodity loser, is higher, at 0.82 .
} 
deteriorate in a down market or recession period (Chordia and Shivakumar, 2002; Cooper, Gutierrez, and Hameed, 2010) and after a low-sentiment period (Stambaugh et al., 2012). Our joint momentum strategy shows significantly positive performance regardless of the market state or sentiment. These results are not consistent with the mispricing argument of Stambaugh et al. (2012), that momentum profits are closely related to overpricing and are thus more prominent after a high-sentiment period, or with the risk-based story of Chordia and Shivakumar (2002), that the momentum strategy is risky because its payoff worsens in bad states. Our results suggest that the joint momentum does a better job managing risk than the stock momentum strategy, in the sense that its payoff is more stable over market states, making the momentum anomaly more puzzling.

Third, we investigate time-varying risk exposures of the joint momentum strategy. Grundy and Martin (2001) report that the momentum's loadings on risk factors are positively related to these risk factors' returns over the momentum strategy's formation period. More importantly, Grundy and Martin (2001) suggest this time-varying risk exposure of momentum as a possible reason for the occasional crashes of the momentum strategy. Compared to the stock-only momentum, our results show that the dynamic risk exposure is highly reduced for the joint momentum strategy, especially with respect to the stock market and value factors. We further examine whether applying the dynamic strategies of Barroso and Santa-Clara (2015) and Daniel and Moskowitz (2016) to our static joint momentum strategy improves its performance but we find that it does not. These results once again confirm that our joint momentum strategy does not depend on the market state, including volatility levels.

Lastly, we examine whether the joint momentum strategy is indeed preferable to the single-market momentum strategies (stock-only or the commodity futures-only momentum strategies) for investors with various utility functions. Because the joint momentum strategy is motivated by the optimal investment strategy for log-utility investors, we expect the utility gain of investing in the joint momentum strategy relative to the single-market momentum strategies to be positive, which is indeed consistent with our results. 
The certainty equivalent wealth gains from investing in the joint momentum strategy relative to investing in single-market momentum strategies are positive for log-utility investors $(0.71 \%$ of wealth gains, on average). Furthermore, those certainty equivalent wealth gains are positive even for power utility investors, in general, except for extremely risk-averse cases. In particular, relative to the stock-only momentum strategy, the joint momentum strategy appears to generate positive gains for all cases considered.

The remainder of the paper proceeds as follows. Section 2 describes the data and variables. Section 3.1 compares the stock momentum and commodity futures momentum. Section 3.2 estimates the growthoptimal portfolio and suggests a joint momentum strategy. Section 4.1 investigates the return distribution of the joint momentum strategies and Section 4.2 examines their time-varying performance. Section 4.3 investigates the time-varying risk exposures of the joint momentum strategies. Section 4.4 examines the outperformance of the joint momentum strategies in terms of certainty equivalent wealth gains. Finally, Section 5 concludes the paper.

\section{Data and variables}

We use US commodity futures data from January 1979 to June 2015 obtained from Datastream. These data comprise daily settlement prices on 32 US commodity futures contracts ${ }^{5}$ on butter, feeder cattle, live cattle, corn, dry whey, ethanol, lean hogs, lumber, milk, oats, rough rice, soybeans, soybean meal, No. 2 red wheat, hard red spring wheat, cocoa, coffee "C," cotton seed, orange juice, Sugar No. 11, coal, Brent Crude Oil, light sweet crude oil, heating oil, gasoline, electricity, copper, gold $100 \mathrm{oz}$, palladium, platinum, silver $5000 \mathrm{oz}$, and natural gas. To compile the time series of futures returns, we assume that we hold the

\footnotetext{
${ }^{5}$ To be exact, our sample starts from 19 commodity futures at the beginning of the sample periods and becomes 32 commodity futures on July 30th, 2007 as the sample commodity futures are gradually added.
} 
nearest contract until the end of the month prior to the maturity month. At the end of that month, we roll our position over to the second-nearest-to-maturity contract and hold that contract until the end of the month prior to maturity. This rolling procedure allows us to minimize problems related to lack of liquidity and to compute returns from holding the same contract instead of switching the contract during the holding month.

In Section 3, for commodity futures momentum portfolios, we sort commodity futures contracts into quintiles (CMOM1, CMOM2, CMOM3, CMOM4, and CMOM5) based on the past $J$-month returns $(J=1$, 3,6 , and 12) in each month and compute the equally weighted monthly return of each quintile. We employ these five portfolios as representative portfolios of the US commodity futures markets to focus on the advantageous effects of investing in commodity futures momentum.

In Section 3, for stock data, we use monthly returns on stock market portfolios, formed on firm size, the book-to-market ratio, profitability, investment, and past returns (momentum), obtained from Kenneth French's website. ${ }^{6}$ Most of these portfolio returns are available from July 1926 onward, but we use data from January 1979 to June 2015 to match the sample period with the commodity futures market data. For stock momentum portfolios, we use French's six portfolios, which are formed monthly on the basis of firm size and momentum $(2 \times 3)$. These six portfolios are the intersection of the two portfolios based on firm size and the three portfolios based on prior two- to 12-month returns. We compute the average of the two portfolios with different sizes in each momentum group and thus finally construct three momentum portfolios (SMOM1, SMOM2, and SMOM3).

In addition to the stock momentum portfolios, we employ monthly returns on the Fama-French (2015) stock market portfolios based on firm size (SIZE), the book-to-market ratio (BTM), profitability $(O P)$, and investment (INV) as stock market portfolios that capture other characteristics. Table 3 of Fama and French (2015) shows the details of portfolio construction for SIZE, BTM, OP, and INV. For each characteristic

\footnotetext{
${ }^{6}$ See http://mba.tuck.dartmouth.edu/pages/faculty/ken.french/data_library.html.
} 
except SIZE, we form three portfolios. For SIZE, we form two portfolios (SIZE1 and SIZE2). Consequently, we have 11 portfolios but we exclude one due to the linear dependence between the 11 portfolios. $^{7}$ Specifically, of the three BTM portfolios (BTM1, BTM2, and BTM3), we exclude BTM2, which indicates the portfolio of firms with a medium book-to-market ratio level. Finally, using the three-month Treasurybill rate as the risk-free rate, we compute the excess returns on each portfolio.

Following Fama and French (2015), we also construct risk-mimicking portfolios using these stock and commodity futures portfolios. The size $(S M B)$, value $(H M L)$, investment $(C M A)$, profitability $(R M W)$, stock momentum $(S W M L)$, and commodity futures momentum ( $C W M L J$ for $J=1,3,6$, and 12$)$ factors are defined as (SIZE1 - SIZE2), (BTM3 - BTM1), (OP3 - OP1), (INV1 - INV3), (SMOM3 - SMOM1), and (CMOM5 $-C M O M 1$ ) for $J=1,3,6$, and 12 , respectively.

In Section 4, we use monthly data for all common stocks (share codes 10 and 11) on the New York Stock Exchange (NYSE), American Stock Exchange, and NASDAQ. The data are obtained from the Center for Research in Security Prices (CRSP). For the sample period of stock portfolio returns, we use monthly data for common stocks from January 1979 to June 2015.

In contrast to stocks, futures are zero-investment securities, which means there is no initial investment. Thus, the returns on commodity futures should be considered excess returns, which cannot be compared directly with returns on stocks (Bodie and Rosansky, 1980; Daskalaki and Skiadopoulos, 2011). We use the three-month Treasury bill rate provided by Datastream as the risk-free rate and then convert stock returns into excess returns to make the returns on stocks and commodity futures comparable.

\footnotetext{
${ }^{7}$ Specifically, $9 \times(S I Z E 1+S I Z E 2)=2 \times(B T M 1+B T M 2+B T M 3+O P 1+O P 2+O P 3+I N V 1+I N V 2+$ INV3).
} 


\section{Selling commodity futures losers}

\subsection{Descriptive statistics}

To start, we examine the descriptive statistics on the stock and commodity futures momentum portfolios during our sample period and compare them with previous findings in the literature.

\section{[Insert Table 1]}

Table 1 presents sample statistics for monthly excess returns on the stock and commodity futures portfolios. A portfolio with a large number indicates a portfolio with firms that have a high value of the specific characteristic. For example, INV3 indicates a portfolio with firms that have the highest value of the investment variable (INV) and SMOM3 (CMOM5) indicates a portfolio with stocks (commodity futures contracts) with the highest past returns, which is also called the stock winner (commodity futures winner). Similarly, we call SMOM1 (CMOMI) the stock loser (commodity futures loser). The table shows the mean, standard deviation, skewness, and kurtosis of (excess) returns.

First, the average returns on stock portfolios confirm the effects documented by Fama and French (2015). Small firms (SIZE1) outperform big firms (SIZE2) and value firms (BTM3) outperform growth firms (BTM1). In terms of profitability and investment, firms with robust operating profitability $(O P 3)$ have larger returns than firms with weak operating profitability $(O P l)$ and firms with conservative investment (INV1) have larger returns than firms with aggressive investment (INV3). Table 1 also confirms the stock momentum effect and the commodity futures momentum effect. The stock (commodity futures) winner shows larger average returns than the stock (commodity futures) loser does. The monotonically increasing pattern of average returns on commodity futures portfolios is consistently observed for all values of $J$. 
The skewness and kurtosis of stock momentum portfolios seem to be consistent with the results of Daniel and Moskowitz (2016). They document that crashes in stock momentum are attributable mostly to the short side, which is the loser portfolio. For example, they note that, in July and August of 1932, the market and the winner portfolio decreased by $82 \%$ and $32 \%$, respectively, while the loser was up by $232 \%$. From March to May of 2009 , the US stock market was up by $26 \%$ but the loser decile was up by $163 \%$. The positive large skewness of the stock loser thus seems to be related to an occasional crash in stock momentum. Our results also show that the skewness and kurtosis of the stock loser (SMOMI) are as large as 0.387 and 4.849 , respectively. The commodity futures losers, however, show much lower skewness and kurtosis. The short-term commodity futures loser (CMOMI with $J=1)$ especially shows the largest differences with the stock loser. Some of the skewness of the commodity futures losers is even negative and their kurtosis is less than $1 / 10$ of the kurtosis of SMOM1. The skewness and kurtosis of CMOM1 appear to increase as $J$ increases, but they remain lower than those of $S M O M 1$, even for the case in which $J=12$. The commodity futures winners (CMOM5) also show lower skewness for all $\mathrm{J}$ values, except for the $J=1$ case; all CMOM5s show a much larger kurtosis compared to that of the stock winner (SMOM3).

Moreover, we find differences between the distributions of the stock and commodity futures portfolio returns sorted on past returns (SMOMs and $C M O M \mathrm{~s})$. First, all three stock portfolios sorted on past returns have positive average returns $(0.41 \%, 0.72 \%$, and $1.02 \%)$, while the commodity futures winners have positive average returns (ranging from $0.63 \%$ to $1.00 \%$ ) and the commodity futures losers have negative average returns (ranging from $-0.55 \%$ to $-0.27 \%$ ). When we compare the returns of winners (CMOM5 and SMOM3), their average returns seem to be comparable, whereas the commodity futures loser (CMOM1) seems to considerably underperform the stock loser (SMOM1), on average. Next, the commodity futures winner (CMOM5) tends to have especially high kurtosis (ranging from 2.054 to 6.226 ) relative to other portfolios, while the stock winner (SMOM3) has lower kurtosis than the stock loser (SMOM1). 
These differences confirm our motivation for combining the commodity futures momentum with the stock momentum. If we combine the stock and commodity futures momentums, we may reduce the skewness and kurtosis of the strategy, thus effectively reducing the possibility of a crash. Specifically, we see this possibility, especially from the short side, which is the loser portfolio.

[Insert Table 2]

As in Table 1, Table 2 shows the positive average returns of all factors and confirms the various risk premiums in the stock market documented in the literature, such as size or value premiums (Carhart, 1997; Fama and French, 2015), and commodity futures momentum (Kang and Kwon, 2017). Compared to the stock market factors $S M B, H M L, C M A, R M A$, and $S W M L$, commodity futures momentum factors (CWMLJ for $J=1,3,6$, and 12) show much higher mean returns and larger standard deviations. The commodity futures momentums seem to be highly correlated with each other (correlations ranging from 0.349 to 0.704 ) but have low correlations with stock market factors. Correlations between the stock momentum (SWML) and the commodity futures momentums $(C W M L s)$ are also quite small. Their absolute values are less than 0.037 and they are even negative in the case of $J=3$ and $J=6$. In the case of $J=12, S W M L$ shows a positive correlation with $C W M L$, consistent with Pirrong (2005) and Kang and Kwon (2017), but it is small, at $0.037 .^{8}$

\footnotetext{
${ }^{8}$ Our results show a much smaller correlation between the stock momentum and the commodity futures momentum relative to the results of Asness et al. (2013). Asness et al. (2013) report the significant correlation between the global stock momentum and the commodity momentum, which is 0.20 . If we follow their weighting method, which assigns a larger weight on a stock with larger past returns and thus includes all sample stocks in the momentum portfolio, and their ranking and holding period for the momentum strategy, then our stock momentum and commodity momentum also show a correlation of 0.17 . If we include only stocks on the NYSE to construct the stock momentum, then the
} 
In terms of skewness and kurtosis, Table 2 also shows results consistent with those in Table 1 . Table 2 shows that the stock momentum factor portfolios $(S W M L)$ have a skewness of -1.461 and a kurtosis of 11.332, while the short-term commodity futures momentum factor portfolios ( $C W M L 1)$ have a skewness of 0.160 and a kurtosis of 0.571 . In January 2001, during a US recession period, the stock momentum factor portfolio experienced a large negative return $(-25 \%)$. The 12-month commodity futures momentum factor portfolio $(C W M L 12)$ also experienced a negative return $(-15.6 \%)$, but the one-month commodity futures momentum factor portfolio $(C W M L 1)$ experienced a negative return of $-7 \%$. In April 2009, around the global financial crisis, the stock momentum factor portfolio also showed a large negative return (-34.6\%), but the commodity futures momentum factor portfolios showed no extreme returns. ${ }^{9}$

\subsection{Combining stock and commodity futures momentums}

The results described in Section 3.1 indicate the different natures of the two momentums and show favorable features of the commodity futures momentum (especially the loser side) relative to the stock

correlation becomes slightly larger, at 0.18 . Thus, the different correlations of Asness et al.'s (2013) study and our study can be attributed to the construction of the momentum strategy.

${ }^{9}$ We also examine the return distribution and correlations around the global financial crisis - from January 2007 to December 2010 - to investigate whether the smaller skewness and kurtosis of the commodity futures momentums and the low correlation between the commodity futures momentum and the stock momentum still remain even during the crisis. The results are reported in Table A1 in the Appendix. We find that the correlation between $C W M L 12$ and $S W M L$ appears to be increased but still not substantially large (0.221). Moreover, the shorter-term commodity futures momentums (CWML1, CWML3, and CWML6) show even much lower correlations (negatively larger correlations) with $S W M L$ during the crisis. The higher moments of returns (skewness and kurtosis) on commodity futures momentums are also much smaller in absolute value compared to those on the stock momentum. 
momentum. Daniel and Moskowitz (2016) document that crashes in stock momentum are attributable to the short side and, thus, selling the commodity futures loser can be a key to alleviating the momentum crash effect. We further examine this issue by estimating the growth-optimal portfolio in this section. Asness et al. (2013) examine momentum in global markets by averaging return series computed using equal volatility weights across eight diverse markets and asset classes, but their purpose is not to construct an optimal momentum strategy across markets. An effective way to combine momentums in different asset classes or markets has rarely been examined in the literature.

To estimate the growth-optimal portfolio, we estimate the optimal portfolio for a single-period logutility investor. Hakansson and Ziemba (1995) show that the central feature of the growth-optimal investment strategy is the logarithmic shape of the objective function. That is, the growth-optimal portfolio is the optimal portfolio for log-utility investors. Specifically, we estimate the portfolio weights satisfying the following optimality condition for log-utility investors:

$$
E_{t}\left[\frac{1+r_{i, t+1}}{1+r_{p, t+1}}\right]=1
$$

where $r_{p, t+1}$ is the return on the optimal portfolio and $r_{i, t+1}$ is the return on each portfolio $i$ in our test set. Since the growth-optimal portfolio can be interpreted as the optimal portfolio for a single-period log-utility investor, our analysis can be criticized because of its limited application for other utility functions. However, Hakansson and Ziemba (1995) document that, in the long run, the growth-optimal portfolio can be an optimal choice, even for other types of utility functions, and Long (1990) shows that it can serve for the numeraire portfolio that prices all the assets in the market, even when investors have utility functions other than the log-utility function.

In addition to the stock and commodity futures momentum portfolios (SMOM1, SMOM2, SMOM3, CMOM1, CMOM2, CMOM3, CMOM4, and CMOM5), we employ the set of stock market portfolios (SIZE1, 
SIZE2, BTM1, BTM3, OP1, OP2, OP3, INV1, INV2, and INV3) to control for other effects. ${ }^{10} \mathrm{We}$ only consider those portfolios motivated by Merton's (1973) intertemporal asset pricing model and the FamaFrench five-factor model. According to Merton's intertemporal asset pricing model, investors invest only in risk factors, which are the market portfolio and hedge portfolios, among risky assets. ${ }^{11}$ Because the Fama-French five-factor model is one of the most popular asset pricing models in the literature, we choose the SIZE, BTM, OP, and INV assets in addition to SMOM and CMOM as the constituents of our investment universe. ${ }^{12}$ Thus, we search for the growth-optimal portfolio for the case where the investment set is expanded from the universe consisting of stocks in the Fama-French five-factor plus stock momentum factor world to the universe including the commodity futures momentum portfolios in addition to stocks. Table 3 shows the estimated growth-optimal portfolio weight on each asset in our investment universe

\footnotetext{
${ }^{10} \mathrm{We}$ also estimate optimal portfolio weights based on the set of momentum-only portfolios, SMOM and CMOM, but we draw a similar conclusion, that the optimal portfolio has positive weights on stock winners and negative weights on commodity losers.
}

${ }^{11}$ This motivation also includes the assumption that the multifactor model can be regarded as a variant of the intertemporal capital asset pricing model (ICAPM) as Fama (1991) documents. Maio and Santa-Clara (2012) criticize this assumption and empirically show that many of popular multifactor models indeed fail to satisfy the necessary conditions to be a variant of the ICAPM. However, they show that Fama and French's (1993) three-factor model and Carhart's (1997) four-factor model satisfy those conditions and thus can be regarded as a variant of the ICAPM. We appreciate the anonymous referee to clarify this issue.

\footnotetext{
${ }^{12}$ Fama and French (2018) show that the momentum portfolios cannot be spanned by the Fama-French five factors. Thus, the addition of the momentum portfolios can be justified. The market portfolio is excluded from the list of assets in our investment universe because it can be synthesized by the five momentum portfolios.
} 
during our sample period. The results for the commodity futures portfolios formed on the past $J$-month returns for $J=1,3,6$, and 12 are reported.

\section{[Insert Table 3]}

In Table 3, the weights on the commodity futures portfolios show a consistent pattern, buying winners and selling losers in the commodity futures markets. Specifically, we find a common pattern for all values of $J$, where the weights on the portfolios with low past returns (CMOM1 and CMOM2) are negative in all cases and statistically significant in many cases. The portfolios with high past returns (CMOM4 and CMOM5) also show positive weights in most cases. In fact, the weights on CMOM5 are all positive and significant. The weights on CMOM4, however, are negative and significant in the case of $J=1$ and $J=6$.

On the other hand, all the stock momentum portfolios carry positive weights in the optimal portfolio, in stark contrast to the commodity futures momentum. While the commodity futures portfolios with low past returns, $C M O M 1$ and $C M O M 2$, consistently show negative weights, the stock losers (SMOM1) notably have weights as large and significant as those of the stock winners (SMOM3). Thus, the optimal weights on the commodity futures loser and the stock loser show striking differences. The stock winner and the commodity futures winner both have positive weights in all cases, but their size differences are noteworthy. The weights on SMOM3 range from 33.5 to 42.6, while those on CMOM5 range from 1.2 to 2.4. Overall, the results in Table 3 suggest that buying the stock winner and selling the commodity futures loser is optimal for investors pursuing the growth-optimal strategy.

Overall, given the low correlations between stock momentum and commodity futures momentum factor portfolio returns, different exposures of stock and commodity futures momentum factors to the business cycle (market crashes), and the high profitability of the commodity futures momentum factor portfolios, we expect that the performance of a momentum portfolio can be improved by incorporating the commodity futures market and the stock market into the investment universe. More importantly, our results 
in Section 3 consistently suggest that the short position on the commodity futures loser should be included in the optimal momentum portfolio. In addition to the commodity futures loser's favorable features in historical distribution compared to the stock losers, the growth-optimal portfolio suggests the long position in the commodity futures winner and the short position in the commodity futures loser. Compared to the positions on the stock winner and loser, the stock loser shows large and positive weights unlike the commodity futures loser, but the stock winner shows much larger and more positive weights than the commodity futures winner.

Based on these findings, we suggest a strategy of buying the stock winner and selling the commodity loser, which we call the joint momentum strategy. We expect substituting the commodity futures loser for the stock loser to be more attractive than selling stocks, even from the implementation point of view. Selling commodity futures is a more implementable strategy than selling stocks. Commodity futures offer leverage and are not subject to short-selling restrictions, unlike stocks. In the stock markets, the short seller is charged interest for the loan of the security, which is called the loan fee, and several restrictions, such as the uptick rule, make short selling difficult or even impossible to implement. As D'Avolio (2002) reports, the shortselling cost is sometimes prohibitively high. In addition, short sellers in the stock market are exposed to the short-selling risk of stock loan recalls and increasing loan fees (Engleberg et al., 2018). This difference in short-sale costs between stocks and commodity futures is important from the perspective of previous studies, such as those of Lesmond et al. (2004) and Stambaugh et al. (2012). Our joint strategy is free from this issue. Moreover, since we use the price of the nearest contracts that are liquid with relatively small transaction costs, selling commodity futures rather than selling stocks is much easier to implement and entails lower costs. Barroso and Santa-Clara (2015) note an ongoing debate on whether plain (original stock) momentum is economically exploitable after transaction costs. Daniel and Moskowitz (2016) document that their dynamic momentum strategy dramatically improves performance relative to traditional and other modified momentum strategies, but they also document that the actual implementation of their modified strategy would be accompanied by higher transaction costs. Our joint momentum strategy is expected to 
incur even lower transaction costs than the traditional stock momentum strategy, since selling in the commodity futures markets is less costly in terms of transaction costs and easier to implement.

\section{Joint momentum strategy}

\subsection{Return distribution of the joint momentum strategy}

In Section 4, we investigate the performance of the joint momentum strategy, buying the stock winner and selling the commodity futures loser, in various aspects. First, in this section, we investigate the return distributions of the momentum strategy in each of the stock and commodity futures markets and the joint momentum strategy. We use individual stock data provided by the CRSP to construct momentum portfolios instead of French's momentum portfolios to explore various choices of ranking periods, but we mainly report the results for the 12-month stock momentum $(\mathrm{Jl}=12)$ following the conventional methodology of forming momentum portfolios in the literature (Asness et al., 2013) and highlight the results of other ranking periods if necessary. For the commodity futures momentum, we choose two ranking periods: one month and 12 months $(J 2=1$ and $J 2=12) .{ }^{13}$ Following convention, we examine the 12-month commodity futures momentum as well as the 12-month stock momentum and we additionally examine the one-month

\footnotetext{
${ }^{13}$ Unlike the commodity futures momentum strategy, we exclude the one-month ranking period case for the stock momentum strategy, since the stock momentum strategy traditionally excludes the prior month's return because of market microstructure issues or the reversal effect (Stambaugh et al., 2012; Asness et al., 2013; Fama and French, 2018). For example, for the $J 1=12$ strategy, the portfolio at month $t$ is formed on the return from month $t-12$ to month $t-2$, whereas, for the $J 2=12$ strategy, the portfolio at month $t$ is formed on the return from month $t-12$ to month $t-1$.
} 
commodity futures momentum for several reasons. ${ }^{14}$ First, the one-month commodity futures momentum returns show the lowest correlation with the stock momentum returns and the one-month commodity futures loser shows the largest negative return in Table 2. Shen et al. (2007) also report that the one-month momentum is strongest in the commodity futures markets. Moreover, the one-month commodity futures loser also shows the greatest differences in skewness and kurtosis compared to the stock loser in Table 1. Second, in the growth-optimal portfolio (Table 3), we find that the one-month case shows that the commodity futures loser has the largest negative weight of the other choices of ranking periods. The 12month commodity futures loser appears to have the second largest weight (in absolute value).

Following the construction of French's momentum decile portfolios, ${ }^{15}$ at the end of each month, the stocks are split into 10 momentum groups ${ }^{16}$ based on their returns over the previous $J 1$-month ranking period using NYSE breakpoints. For commodity portfolios, the commodity futures contracts are sorted into quintiles based on their returns over the previous $J 2$-month ranking period. The top decile (quintile) portfolio is assigned as a stock (commodity) winner portfolio and the bottom decile (quintile) portfolio is assigned as a stock (commodity) loser portfolio. Momentum strategies indicate buying the winner and selling the loser. We call the resulting stock-only and commodity futures-only momentum strategies the $J 1$

\footnotetext{
${ }^{14}$ We examine the various combinations of ranking periods of one, three, six, and 12 months and holding periods of one, three, six, and 12 months but report the results for only selected strategies, for brevity. The other cases are available upon request. The results become weaker as the holding period increases but the overall results appear to be qualitatively similar.

${ }^{15}$ See http://mba.tuck.dartmouth.edu/pages/faculty/ken.french/Data_Library/det_10_port_form_pr_12_2.html.

${ }^{16}$ We also split stocks into three portfolios instead of 10 portfolios and confirm qualitatively similar results.
} 
and $J 2$ momentum strategies, respectively. We call the joint strategy buying the $J 1$-month stock winner and selling the $J 2$-month commodity futures loser the $J 1 / J 2$ momentum strategy. ${ }^{17}$

\section{[Insert Table 4]}

Panel A of Table 4 presents the summary statistics of returns on the $J 1 / J 2$ joint momentum strategies. The average monthly returns on the $J 1 / J 2$ strategies are almost $2 \%$ and highly significant. The $12 / 1$ strategy generates the largest average return, at $1.907 \%$, with a Sharpe ratio of 0.822 . The annualized Sharpe ratios and average returns of these joint strategies are much higher than for the 12-month stock momentum strategy. The Sharpe ratios of stock-only momentum strategies never exceed 0.358 in Panel A of Table A2 in the Appendix and the annualized Sharpe ratios of the S\&P 500 and Russell 2000 for the same sample period are less than 0.3 ; thus, we see that these joint strategies strongly outperform other stock indexes. The $J 1 / J 2$ strategies also show higher Sharpe ratios and returns than the $J 2$ commodity futures momentum strategies.

In the literature on commodity futures, the basis, which is the difference between the spot price and the futures price, ${ }^{18}$ is regarded an important risk factor and many studies report a significant relation between the basis factor and the momentum factor in commodity futures markets (Miffre and Rallis, 2007; Gorton et al., 2012; Szymanowska et al., 2014; Kang and Kwon, 2017). We control for the basis effect by constructing double-sorted commodity futures momentum portfolios. We first sort futures contracts by

\footnotetext{
${ }^{17}$ To be exact, returns on both the stock winner and commodity futures loser are computed in excess returns and, thus, all of the long legs, short legs, as well as long-short momentum strategies are zero-investment strategies.

${ }^{18}$ Spot price data are not available for most commodities (Fama and French, 1987; Gorton et al., 2012; Kang and Kwon, 2017). Thus, we employ the price of the nearest futures contract as the spot price and the price of the secondnearest futures contract as the futures price. Then, the basis is defined as the logarithm of the nearest contract's price divided by the second-nearest contract's price.
} 
basis into three groups and then sort the contracts in each group by the previous $J 2$-month returns into three groups. After constructing the nine portfolios by double sorting, we average three winner (loser) portfolios from three basis groups and call the resulting portfolio the commodity futures winner (loser). Panel B of Table 4 presents the joint momentum strategies based on the commodity futures winner and loser portfolios constructed from the double-sorted portfolios, as well as the stock winner and loser portfolios.

Compared to the results in Panel A of Table 4, the basis-controlled strategies show reduced returns in all cases but the reduction in returns is small and the returns of these strategies remain highly significant. Thus, Panel B shows that the profitability of the joint strategy of buying the stock winner and selling the commodity futures loser is not driven by the basis effect. Though not tabulated in this paper, we also test whether the profitability of the joint strategy can be explained by the Fama-French three- and five-factor models $(1993,2015)$ and the Carhart four-factor model (1997). ${ }^{19}$ We run the time-series regression with these three test models and examine whether the intercept, the unexplained profits of the $J 1 / J 2$ joint momentum strategy, is significant. The three test models do not show substantial differences in explaining the joint momentum profits and the intercepts appear to be significant in all cases. These results show that the profitability of the joint momentum strategy is robust to traditional risk factor models.

The joint momentum strategy shows a dramatic reduction in skewness and kurtosis, as expected. According to the results presented in Table A2 in the Appendix, the skewness of the stock-only momentum ranges from -3.320 to -2.493 and its kurtosis ranges from 21.872 to 25.431 . The skewness of the commodity futures-only momentum ranges from -0.140 to 0.302 and its kurtosis ranges from 0.721 to 2.296. Panel A of Table 4 shows that the $J 1 / J 2$ strategies provide much lower skewness $(0.036$ and -0.081$)$ and kurtosis

19 The factors of Fama and French's three- and five-factor models are obtained from French's website (http://mba.tuck.dartmouth.edu/pages/faculty/ken.french/data_library.html). For the stock momentum factor of Carhart's model, we employ the return on the $J 1$ stock momentum strategy if the test strategy is the $J 1 / J 2$ joint momentum strategy instead of the stock momentum factor provided by French's website. 
(1.273 and 2.113) in absolute value than the single-market momentum strategies. The improvement in higher-order moments from the joint momentum strategy is comparable to that from the strategies suggested to reduce the tail risk of the stock-only momentum strategy. For example, Barroso and Santa-Clara (2015) report that, during their sample period, the skewness and kurtosis of the traditional stock momentum strategy are -2.47 and 18.24 , respectively, but -0.42 and 2.68 , respectively, for their constant volatility strategy. Moreover, Panel B also shows that the improvement in higher-order moments holds, even after controlling for the basis effect.

In untabulated results, we construct the commodity futures return series by selecting the second-nearest contract instead of the nearest contract at the end of each month, and compute returns on the commodity futures momentum and the joint momentum strategies as another robustness check. We find that the results are qualitatively the same. For example, in Panel A of Table 4, we find that the 12/1 joint momentum strategy with the nearest contract generates an average return of $1.907 \%$ with t-statistics $=4.59$ while that with the second-nearest contract generates an average return of $1.779 \%$ with t-statistics $=3.96$. In case of the $12 / 12$ joint momentum strategy, selecting the second-nearest contract even appears to generate the higher average return, that is $1.722 \%$ with t-statistics $=4.22$. The Sharpe Ratios for both the $12 / 1$ and the 12/12 joint strategies also remain similar. Specifically, Panel A of Table 4 shows that the 12/1 and the 12/12 joint strategies with the nearest contracts have Sharpe Ratios of 0.822 and 0.752 , respectively, and these with the second-nearest contracts have 0.816 and 0.774 , respectively.

In summary, we investigate the profitability of a strategy that utilizes the outperformance of stock winners and the underperformance of commodity losers and find that this joint strategy greatly outperforms the momentum strategy in each individual market in terms of average returns and Sharpe ratios. This higher performance is also consistent with the results in Section 3.2, in that selling losers in commodity futures is the optimal portfolio strategy for investors who can invest in the commodity futures market as well as in the stock market. More importantly, consistent with our expectations, our results show that the skewness 
and kurtosis of the joint momentum strategy are dramatically reduced in absolute value relative to the stock momentum strategy. Considering the extensive literature addressing the problem of the high negative skewness and high kurtosis of the stock momentum strategy, our joint strategy could serve as an alternative momentum strategy to alleviate this problem.

\subsection{Time-varying performance of the joint strategy}

In this section, we investigate the time-varying performance of the joint strategy depending on market conditions. In Section 4.1, we document that one of our motivations for combining the stock momentum and the commodity futures momentum is the possibility of reducing the tail risk of traditional stock momentum. We confirm that the joint strategy greatly improves skewness and kurtosis, thus supporting our expectations. In addition to the skewness and kurtosis, because the literature on momentum documents that occasional crashes occur in bear markets or during market rebounds, it is worth investigating how our joint strategy performs depending on market conditions. If the strategy generates positive returns, even in a bad market state, in contrast with the findings on stock momentum, then this result will represent another positive characteristic of the strategy that investors might like.

Though each study on the time-varying profitability of stock momentum defines market states in its own way, the results consistently suggest that stock momentum generates significant returns under good market conditions. In other words, stock momentum strategies generate high returns when the market is in a good state and low returns when it is in a bad state. Chordia and Shivakumar (2002) report that stock momentum generates significant returns in an expansionary period but not in a contractionary period. Cooper et al. (2004) show the significance of stock momentum only in a good market state. Splitting the sample by level of investor sentiment, Stambaugh et al. (2012) show that stock momentum generates much larger returns in the high-sentiment period than in the low-sentiment period; they also document that this 
difference is driven by the short leg, the performance of the loser portfolio. By contrast, the time-varying profitability of the commodity futures momentum is relatively unexplored but studies suggest that profitability can vary with market conditions or the economic environment. In the literature on the diversification benefits of commodity futures, Jensen et al. (2000) report that, in restrictive monetary policy periods, efficient portfolios place significant weights on commodity futures and including commodity futures in the portfolio increases profitability.

We define market states in two ways. First, following Chordia and Shivakumar (2002), we split the sample into two economic environments — expansionary and contractionary (recessionary) periods — using the definition of the National Bureau of Economic Research (NBER) ${ }^{20}$ Second, we employ Baker and Wurgler's (2006) sentiment index ${ }^{21}$ and categorize a month as a high-sentiment (low-sentiment) month if the value of the sentiment index in the previous month is above (below) the median value for the sample period. These two standards for classifying the sample period differ from each other. The NBER definitions for expansion and contraction are based on the movement of various macroeconomic variables, such as the real gross domestic product and real income, and we can thus directly investigate the relation between the strategy's profitability and the business cycles of the US economy. On the other hand, the Baker-Wurgler sentiment index is defined as the first principal component of six measures of investor sentiment, which are the closed-end fund discount, the number of and the first-day returns of initial public offerings, the NYSE turnover, the equity share in total new issues, and the dividend premium. Baker and Wurgler (2006) show that the investor sentiment index is not related to the business cycle variables and might therefore not be related to economic conditions. Considering the motivation behind the construction of the sentiment index,

\footnotetext{
${ }^{20}$ See www.nber.org/cycles.html.

${ }^{21}$ The sentiment index data are obtained from Wurgler's website (http://people.stern.nyu.edu/jwurgler).
} 
this index is likely to be more closely associated with the behavioral aspects of market participants, such as overconfidence and optimism. $^{22}$

First, we use the NBER definitions for expansionary and contractionary periods and then compute average monthly returns on the stock-only $(J 1)$, commodity futures-only $(J 2)$, and joint momentum strategies $(J 1 / J 2)$. In addition, we compute the average monthly (excess) returns on the stock winner, stock loser, commodity futures winner, and commodity futures loser in each period.

\section{[Insert Table 5]}

Panel A of Table 5 shows that the stock momentum strategy generates a slightly more significant return in the expansionary period than in the contractionary period. Though the difference in returns seems to be small in the case of $J 1=12$, we find that, in the case of $J 1=3(J 1=6)$, the average returns on the stock momentum are $0.234(0.386)$ and $-0.188(0.160)$ in the expansionary and contractionary periods, respectively, though not tabulated here. This pattern is consistent with the findings of Chordia and Shivakumar (2002). The commodity futures momentum strategies show a similar pattern, that is, they

\footnotetext{
${ }^{22}$ We appreciate the comment of the anonymous referee that Baker and Wurgler's (2006) sentiment index captures the investor sentiment especially in the stock markets and thus its effects on commodity futures can be limited as opposed to stocks. However, we expect that the commodity futures momentum would be also affected by this sentiment index because Asness et al. (2013) document the commonality among momentums in various asset markets and Stambaugh et al. (2012) report that the stock momentum is highly sensitive to the market sentiment. In fact, the 12-month commodity futures momentum strategy also shows that it generates insignificant returns in the low sentiment period (average return $=0.604$ with t-statistics $=1.12$ in Table 5) as the 12-month stock momentum strategy does, which shows that the commodity futures momentum is also sensitive to the sentiment. Moreover, Lutzenberger (2014) also reports that Baker and Wurgler's (2006) sentiment index has a predictive power even in the commodity futures market, and thus it could be another motivation to employ the sentiment index in our analysis.
} 
generate larger and more significant profits during the expansionary period. ${ }^{23}$ The positive but less significant profits in the contractionary period could be due to the small sample size during the contractionary period, ${ }^{24}$ but we observe that the returns in the expansionary period are larger than in the contractionary period. Though the movement of the returns on the stock and commodity futures momentum strategies seems to be similar, the returns on the commodity futures winner and loser appear to differ from those on the stock winner and loser. We find that the returns on both the commodity futures winner and loser decrease in the contractionary period, which is in sharp contrast with the increasing pattern of returns on the stock winner and loser. Thus, commodity futures momentum profits become much smaller and less significant in the contractionary period because the returns on the winner decrease much more than the returns on the loser in this period.

The results from single-market momentums shed light on the improved profitability of our joint strategy in the contractionary period. The stock winner tends to outperform but the commodity futures loser tends to underperform more in the contractionary period than in the expansionary period. Table 5 shows the monthly average returns of the $J 1 / J 2$ momentum strategy during the expansionary and contractionary periods, respectively. The returns on the joint momentum strategies are positive and significant at least at the $1 \%$ significance level in both the expansionary and contractionary periods. In the contractionary period, the returns are positive and even much larger than those in the expansionary period. The returns in the

\footnotetext{
${ }^{23}$ This pattern suggests that the commodity futures momentum might be able to play a role of hedging portfolio. Kang and Kwon (2017) indeed provide the consistent results that the commodity futures momentum is negatively related to future GDP growth. They suggest that in the perspective of the ICAPM, this negative relation indicates that commodity futures momentum factor can be interpreted as a hedging portfolio. We appreciate the anonymous referee to point out this.

${ }^{24}$ According to the NBER classification, only 52 of the total of 377 months are categorized as in a contractionary period during our sample period.
} 
contractionary period are less significant, but this could be due to the small sample size for this period. The differences in returns on the joint strategy in the expansionary and contractionary periods are insignificant ( $t$-statistics of -0.87 and -1.07) for both the $J 2=1$ and $J 2=12$ cases, though not tabulated here. More importantly, the joint momentum strategies greatly outperform the stock-only and the commodity futuresonly momentum strategies during the contractionary period.

Next, using the sentiment index constructed by Baker and Wurgler (2006), we compute average monthly returns on the stock-only, commodity futures-only, and joint momentum strategies in the highand low-sentiment periods. As in Panel A of Table 5, we also report average monthly (excess) returns on the stock winner, stock loser, commodity futures winner, and commodity futures loser in each period. The results are reported in Panel B.

Panel B of Table 5 shows that both stock winner and loser portfolios show a big return difference between the high- and low-sentiment periods. It is notable that the winner-minus-loser portfolio generates significant returns only in the high-sentiment period, since the negative return on the loser portfolio contributes to the performance of the stock-only momentum strategy. Both stock winner and loser portfolios show larger returns in the low-sentiment period than in the high-sentiment period and their returns are comparable, which leads to the insignificant long-short return. The findings that stock momentum exists only in the high-sentiment period and the performance of the loser portfolio is a more dominant determinant of momentum are consistent with the results of Stambaugh et al. (2012). They document that, given marketwide sentiment, overpricing is more prevalent than underpricing because of short-sale impediments and, thus, long-short strategies exploiting the anomalies are more profitable on the short side following high sentiment. Our results for the stock-only momentum support this hypothesis.

The commodity futures-only momentum seems to be less affected by sentiment than the stock-only momentum is. The winner portfolios show positive returns in both the high- and low-sentiment periods. The loser portfolios have lower returns in the high-sentiment period than in the low-sentiment period, but 
the difference in returns on the loser portfolios between the high- and low-sentiment periods is not as large as in the case of the stock loser portfolio. In the low-sentiment period, the returns on the commodity futures loser portfolios are not as large as the returns on the stock loser portfolios and, thus, the differences in returns on the commodity futures loser portfolios between two sentiment states are quite small and insignificant. Though not tabulated here, for stock losers, the $t$-statistics of the differences in returns between the two sentiment periods is -2.72 , whereas, for commodity futures losers, they are -0.10 and -1.27 in the cases of $J 2=1$ and $J 2=12$, respectively. The result that the performance of the commodity futures loser does not significantly depend on sentiment again supports the hypothesis of Stambaugh et al. (2012), in the sense that there is little restriction on short selling in the commodity futures market. Thus, this supports our argument that our new joint strategy is free from the issue of short-sale costs.

Lastly, in contrast to the single-market momentum strategies having larger returns in the highsentiment period, the joint momentum strategies generate larger returns in the low-sentiment period. Our results show that the returns on the joint strategies are large and highly significant ( $t$-statistics of 5.14 and 3.41 ) in the low-sentiment period. In the case of $J 1 / J 2=12 / 1$, the return in the low-sentiment period is almost twice as large as in the high-sentiment period. Since we find that the commodity futures loser generates much smaller return differences between the two states, the performance of the stock winner seems to mainly drive the difference in returns on the joint strategy. Our results in Panel B of Table 5 show that the joint strategy greatly improves the returns in the low-sentiment period and, therefore, interpreting the low-sentiment condition as the bad market state, we find these results to be consistent with those in Panel A. The overall results in this section show the advantageous role of the joint momentum strategy generating a positive payoff in the recessionary or low-sentiment period, thus efficiently managing risk. 


\subsection{Time-varying risk exposure}

Grundy and Martin (2001) report that momentum has time-varying exposures to the Fama-French factors. Specifically, the momentum loadings on risk factors are positively related to the returns of these risk factors over the formation period of the momentum strategy. Momentum has positively larger loadings on risk factors when these factors have positive returns during the momentum strategy's formation period. Recent empirical studies have reported that the stock momentum strategy occasionally generates large negative returns and these negative returns are especially notable in bear markets or during market rebounds (Grundy and Martin, 2001; Daniel et al., 2012; Barroso and Santa-Clara, 2015; Daniel and Moskowitz, 2016). Grundy and Martin (2001) suggest this time-varying risk exposure of momentum as a possible reason for those occasional crashes of the momentum strategy.

In the previous section, we find that our joint strategy improves the performance of the single-market momentum strategy especially in a recession and, thus, our results shed light on reducing time-varying risk exposure of the momentum strategy. To examine the time-varying risk exposure of momentum, we follow the model of Blitz et al. (2011), using dummy variables for the past performance of risk-mimicking portfolios:

$r_{i, t}=\alpha_{i}+\beta_{1, i} R M R F_{t}+\beta_{2, i} S M B_{t}+\beta_{3, i} H M L_{t}+\beta_{4, i} R M R F_{-} U P_{t}+\beta_{5, i} S M B_{-} U P_{t}+\beta_{6, i} H M L_{-} U P_{t}+\varepsilon_{i, t}$

where $r_{i, t}$ indicates the return on the stock-only, commodity futures-only, or joint momentum strategies for month $t$ and $R M R F_{t}, S M B_{t}$, and $H M L_{t}$ indicate the market excess returns, size factor, and value factor, respectively. ${ }^{25}$ We construct a dummy variable for each factor that is equal to one if the factor has a positive return over months $t-12$ to $t-2$ and zero otherwise. The terms $R M R F_{-} U P_{t}, S M B_{-} U P_{t}$, and $H M L_{-} U P_{t}$

\footnotetext{
${ }^{25}$ We confirm qualitatively similar results using the Fama-French five factors, including the $R M W$ and $C M A$ factors.
} 
indicate interaction variables of a factor and the dummy variable of the given factor in month $t$. Moreover, we include the commodity futures market excess return GSCI, which is the excess return on the S\&P GSCI, and the interaction variable GSCI_UP, which is similarly constructed. We also report the adjusted $R$-squared values for the unconditional regression model (excluding interaction variables) and the conditional regression model (including interaction variables) to evaluate the contribution of dynamic risk exposure in explaining momentum. We report the results without and with the commodity futures market variables in Panels A and B of Table 6, respectively.

\section{[Insert Table 6]}

Panel A of Table 6 first shows that the stock-only momentum has strong dynamic exposure to the Fama-French factors (Blitz et al., 2011). The variable $S M B \_U P$ exceptionally shows an insignificant value ( $t$-statistic of 1.50) but $R M R F_{-} U P$ and $H M L_{-} U P$ appear to be quite large (0.965 and 1.339 , respectively) and highly significant ( $t$-statistics of 4.76 and 4.99 , respectively). Compared to the stock-only momentum, the commodity futures-only momentum shows much weaker dynamic exposure to factors and extremely low explanatory power that is even negative in the case of unconditional models. However, these results are not surprising, since Kang and Kwon (2017) note that the commodity futures momentum cannot be fully explained by the stock market factors. These results confirm our motivation to combine the stock and commodity futures momentums since they have low correlations.

Our main interest is the comparison between the stock-only momentum and the joint momentum. The coefficients on the interaction variables show that dynamic risk exposure is highly reduced in the case of the joint momentum strategy compared to the stock-only momentum. The reduction in time-varying risk exposure appears to be notable for the stock market and value factors ( $R M R F$ and $H M L$, respectively). In the case of time-varying exposure to the stock market factor, the coefficient on $R M R F \_U P$ of the stockonly momentum appears to be roughly twice that of the joint momentum. The coefficients on $H M L \_U P$ exhibit a much greater reduction, from 1.339 to $0.341(0.540)$, in combination with the one-month (12- 
month) commodity futures loser. The size factor is the only exception but, in the case of $J 1 / J 2=12 / 1$, the coefficient on SMB_UP is smaller than that of the stock-only momentum. Though the coefficient on $S M B \_U P$ of the $12 / 12$ joint momentum strategy is larger and more significant than that of the stock-only momentum, the difference between the coefficients is quite small.

The adjusted $R$-squared values for the joint momentums are generally large, ranging from 0.432 to 0.477 , compared to the stock-only momentum, but, in terms of the increase in adjusted $R$-squared values by allowing dynamic risk exposure, the improvement in explanatory power for the stock-only momentum is much more dramatic. Panel A of Table 6 shows that the unconditional Fama-French model has an explanatory power of $0.032(3.2 \%)$ for the stock-only momentum, compared to $0.272(27.2 \%)$ for the conditional model, which is roughly nine times larger than for the unconditional model. On the other hand, our joint strategy also shows an increase in the adjusted $R$-squared values by allowing time-varying risk exposure, but this increase is relatively small, from 0.456 to 0.477 (from 0.432 to 0.476 ), in the case of the $12 / 1(12 / 12)$ joint strategy. This result shows that the exposures of the joint momentum strategies to risk factors are stable, regardless of the factor states.

The risk-adjusted return, which is captured by an intercept of the regression, is also noteworthy. The risk-adjusted return of the stock-only momentum strategy appears to be 0.576 , with a $t$-statistic of 1.66 , indicating that it is significant at the $10 \%$ level. On the other hand, both the commodity futures-only and joint strategies show highly significant risk-adjusted returns. More specifically, the 12/1 and 12/12 joint strategies generate roughly $1 \%$ of the monthly risk-adjusted returns, which are 1.144 and 0.967 , respectively, and both are statistically significant at the $1 \%$ level ( $t$-statistics of 4.01 and 3.05, respectively). The conditional asset pricing model does not seem to account for the returns on the joint momentum strategies.

Panel B of Table 6 presents the results for the regression model including the commodity futures market variables, GSCI and GSCI_UP. Overall, the results in Panel B are similar to those in Panel A. Most of the coefficients have similar values and statistical significance as those in Panel A, indicating that 
including the commodity futures market variables does not significantly affect the marginal effects of the Fama-French factors. Moreover, except for the coefficients on GSCI for the joint momentum strategies, both GSCI and GSCI_UP show generally insignificant effects. Including GSCI and GSCI_UP contributes to increasing the explanatory power for the commodity futures-only and joint momentums but, as we find in Panel A, the increase in explanatory power from allowing time-varying risk exposure is large only in the case of the stock-only momentum. Interestingly, the risk-adjusted return of the stock-only momentum becomes insignificant ( $t$-statistic of 0.82 ) upon inclusion of the commodity futures market variables. Those of the commodity futures-only momentum and joint momentum also become less significant in controlling for the commodity futures market variables, but they still remain highly significant. Our joint momentum strategies especially show highly significant risk-adjusted returns ( $t$-statistics of 3.53 and 2.32).

Overall, our results show that the risk exposure of our joint momentum strategy is less time varying than that of the traditional stock-only momentum strategy. Grundy and Martin (2001) suggest that the timevarying risk exposure of the stock momentum contributes to the momentum crashes and the stock momentum literature suggests ways to reduce the tail risk through a dynamic risk-managed momentum strategy rather than the traditional static strategy. For example, Barroso and Santa-Clara (2015) apply an AR(1) model to the realized variance of stocks and then construct a constant volatility momentum strategy using the forecasted variance. They show that this strategy dramatically reduces the skewness and kurtosis of returns. Daniel and Moskowitz (2016) suggest a dynamic momentum strategy based on the ex ante forecasted betas of stocks and show that their strategy even outperforms the constant volatility strategy suggested by Barroso and Santa-Clara (2015). We also examine whether we can reduce the tail risk further by applying the dynamic strategies of Barroso and Santa-Clara (2015) and Daniel and Moskowitz (2016) to our joint momentum strategy, but we find that dynamic joint momentum strategies do not improve the performance of the static joint momentum strategy, which is consistent with the notion that our joint strategy is less exposed to crash risk. This finding once again shows that our joint momentum strategy does not depend on the market state, including volatility levels. 


\subsection{Certainty equivalent wealth gains from the joint strategy}

This section evaluates the outperformance of the joint momentum strategy over the stock-only and commodity futures-only momentum strategies from a different viewpoint. We employ the concept of a certainty equivalent wealth gain to evaluate benefits from investing in the joint momentum strategy. Specifically, we measure the gains from investing in the joint momentum strategy relative to the stock-only or the commodity futures-only momentum strategy by the certainty equivalent increase in wealth. This measure is closely associated with the opportunity cost that Daskalaki and Skiadopoulos (2011) use to assess the economic significance of the difference in performance of two portfolios. For a utility function $U$ of wealth $W$ at time $t$, the certainty equivalent $\psi_{t}$ is defined as

$$
\mathrm{E}_{\mathrm{t}}\left[U\left(W_{t} R_{J, t+1}\right)\right]=E_{t}\left[U\left(W_{t}\left(1+\psi_{t}\right) R_{I, t+1}\right)\right]
$$

where $R_{J, t+1}$ is gross returns on the $J 1 / J 2$ joint momentum portfolio and $R_{I, t+1}$ is gross returns on the single-market momentum portfolio, that is, the $J 1$ stock-only or $J 2$ commodity futures-only momentum portfolio.

This section investigates this effect with two utility functions: the $\log$-utility function $(U(W)=$

$\ln (W))$ and the power utility function $\left(U(W)=\frac{W^{1-\gamma}-1}{1-\gamma}\right.$, where $\gamma=2,4,8,10$, and 20, indicating the level of relative risk aversion, $R R A$ ). The log-utility case can be regarded as a special case of the power utility with $\gamma=1$. The unconditional estimates of the certainty equivalent gain of a log-utility investor and a power utility investor can be defined as the following equations, respectively:

$$
\psi=100 \times\left[\exp \left\{\frac{1}{T} \sum_{t=1}^{T} \ln \left(\frac{R_{J, t+1}}{R_{I, t+1}}\right)\right\}-1\right]
$$




$$
\psi=100 \times\left[\left\{\frac{1}{T} \sum_{t=1}^{T}\left(\frac{R_{J, t+1}}{R_{I, t+1}}\right)^{1-\gamma}\right\}^{\frac{1}{1-\gamma}}-1\right]
$$

where $R_{J, t+1}$ is gross returns on the $J 1 / J 2$ joint momentum portfolio and $R_{I, t+1}$ is gross returns on the single-market momentum portfolio, that is, the $J 1$ stock-only or $J 2$ commodity futures-only momentum portfolio.

\section{[Insert Table 7]}

Table 7 shows the certainty equivalent wealth gains from investing in the joint momentum strategy $(J 1 / J 2$ strategy) relative to the case of investing in the $J 1$ stock-only (Panel A) or the $J 2$ commodity futuresonly (Panel B) momentum portfolio. The certainty equivalent percentage gains are computed for the logutility function and the power utility function (with $R R A=2,4,6,8,10$, and 20) using equations (4) and (5).

In Panel A of Table 7, the certainty equivalent wealth gains of the joint momentum strategy relative to the stock-only momentum strategy for a log-utility investor are positive for both $12 / 1$ and 12/12 strategies, at $1.166 \%$ and $1.033 \%$, respectively. For the power utility function cases, the certainty equivalent gains are positive and much larger than those of the log-utility cases and the values of the certainty equivalent gains increase as $R R A$ increases. This increasing pattern indicates that the joint momentum strategy becomes more attractive than the stock-only momentum strategy as the investor becomes more risk averse. We motivate the construction of the joint momentum strategy from the perspective of log-utility investors by looking at the growth-optimal portfolio when we extend the investment universe from the stock-only investment set to one including commodity futures. Panel A of shows that our joint momentum strategy can be justified even further for more risk-averse power utility investors.

In Panel B of Table 7, we find much smaller values of the certainty equivalent gain than in Panel A and some negative results for highly risk-averse power utility cases. The certainty equivalent wealth gain 
of the joint momentum strategy relative to the commodity futures-only momentum strategy for a log-utility investor is positive for both $J 1 / J 2$ strategies, but their values are $0.283 \%$ and $0.345 \%$, relatively small compared to the results in Panel A. These results indicate that investors using the momentum strategy in the commodity futures market obtain lower utility gains from the joint momentum strategy relative to momentum investors in the stock market. For example, in the case of the 12/12 momentum strategy, the certainty equivalent gain from the joint momentum strategy of buying stock winners and selling commodity futures losers relative to the stock momentum strategy is $1.033 \%$ for a log-utility investor, whereas the certainty equivalent gain relative to the commodity futures momentum strategy is $0.345 \%$, which is less than half of $1.033 \%$, for log-utility investors.

For the power utility function, we find positive gains only for less risk-averse investors. For more riskaverse investors, with $R R A$ equal to and greater than eight in Panel $\mathrm{B}$ of Table 7 , the certainty equivalent gains appear to be negative. A possible explanation for the negative certainty equivalent gain for extremely risk-averse investors is the larger return volatility of the joint strategy relative to that of the commodity futures-only momentum. The difference between the two panels is mainly due to the fact that the increase in average returns from the commodity futures-only momentum to the joint momentum is much smaller than the increase in average returns from the stock-only momentum to the joint momentum. For example, for the choice of $J 1 / J 2=12 / 12$, the Sharpe ratio of the join strategy increases by 0.138 (from 0.614 to 0.752 ) relative to the commodity futures-only strategy, whereas it increases by 0.394 (from 0.358 to 0.752 ) relative to the stock-only strategy. In Panel B, since the increase in average returns from the commodity futures momentum to the joint momentum is much smaller than that from the stock momentum to the joint momentum in Panel A, the certainty equivalent gains are smaller and even become negative for highly riskaverse cases.

In terms of utility, the overall results in Panel B of Table 7 are weaker than the results in Panel A but, in terms of the mean and variance of returns, our joint momentum strategy seems to outperform the 
commodity futures-only momentum strategy. From the mean-variance investor perspective, the Sharpe ratio, which is the ratio of the mean return to the variance of returns, is an important measure for assessing an asset's performance. If we compare the Sharpe ratios of the commodity futures-only momentum strategy and the joint momentum strategy, the Sharpe ratio of the $J 1 / J 2$ joint momentum strategy is larger than that of the $J 2$ commodity futures momentum strategy. Moreover, if we compare the Sharpe ratios in Panel B of Table A2 with those in Table A3 of Appendix, we can see that the Sharpe ratios of the commodity futuresonly momentum strategies decrease substantially after the basis effect is controlled for, whereas Panel B of Table 4 shows that the Sharpe ratios of the joint strategies are less affected. For example, the Sharpe ratio of the one-month commodity futures strategy is reduced from 0.710 to 0.540 by controlling for the basis effect, but that of the $12 / 1$ joint strategy shows a smaller decrease, from 0.822 to 0.738 . Thus, for a meanvariance investor, our joint strategy can still be interpreted as better than the commodity futures-only momentum strategy or the stock-only momentum strategy.

To summarize, we find improved average returns and Sharpe ratios from combining the stock momentum and the commodity futures momentum by buying stock winners and selling commodity futures losers. We also generally find positive certainty equivalent wealth gains relative to stock-only momentum and commodity futures-only momentum strategies, except in highly risk-averse investor cases. Specifically, for power utility investors with high RRAs, we find negative gains relative to commodity futures-only strategies, probably because of the increase in return volatility for the joint momentum strategy. However, these results are based on the assumption that investors invest all their money in the given portfolio. Considering our findings in Section 4.2, that the joint momentum strategy shows better performance in bad states relative to other strategies, it is highly probable that, if investors invest in the joint momentum strategy as part of their portfolios, this strategy will contribute to their welfare, even though it increases volatility. Moreover, the certainty equivalent wealth gains for power utility investors appear to be larger when the alternative strategy is the stock-only momentum strategy rather than the commodity futures-only momentum strategy. These results show that the joint momentum strategy can be attractive to investors in 
terms of utility, as well as the average return or Sharpe ratio, and they also confirm that extending the investment universe to commodity futures in addition to stocks benefits investors.

\section{Conclusion}

This paper seeks an improved momentum strategy by combining stock momentum with commodity futures momentum. We propose momentum strategies that involve buying stock winners and selling commodity futures losers and show that our suggested momentum strategies effectively improve higherorder moments of returns. Specifically, they reduce the tail risk of returns and outperform the stock-only and commodity futures-only strategies during a recession or after a low-sentiment period and thus provide stable profits, regardless of market conditions. In addition, they even provide higher average returns, larger Sharpe ratios, and greater utility gains relative to the stock-only momentum and commodity futures-only momentum strategies.

Our analyses provide consistent and concrete evidence of the joint strategy's outperformance but they also have limitations. Commodity futures are not the only candidate market to which stock (momentum) investors extend their investment universe, as Asness et al. (2013) document that the momentum phenomenon can be observed in various non-stock asset markets. Our motivation for combining the stock and the commodity futures momentums is that the commodity futures market has been considered more separate from the equity market than other financial markets are and we can thus expect hedging benefits by additionally investing in commodity futures. The substantially low correlation between commodity futures momentum and stock momentum also attracted our attention. Because of these features of commodity futures, our joint momentum strategy can avoid momentum crashes. We thus suggest a new approach to resolve momentum crashes by extending the investment universe, which is distinctive from 
existing approaches involving dynamic strategies (Barroso and Santa-Clara, 2015; Daniel and Moskowitz, 2016) or looking at the residual momentum (Blitz et al., 2011).

Overall, we document that stock-only momentum profits can be improved by extending the investment universe into one including commodity futures. Our joint momentum strategy is easier to implement and generates profits regardless of market conditions, without much exposure to crash risk.

\section{Acknowledgments}

This work was supported by the Ministry of Education of the Republic of Korea and the National Research Foundation of Korea (NRF-2017S1A5B5A07064108). 


\section{Data citation}

[Stock portfolios] Fama, E.F., French, K.R.; 2015; U.S. Research Returns Data; Kenneth French's data library; http://mba.tuck.dartmouth.edu/pages/faculty/ken.french/data_library.html

[NBER business cycle indicator] National Bureau of Economic Research, 2010; US Business Cycle Expansions and Contractions; NBER; www.nber.org/cycles.html

[Sentiment index] Baker, M., Wurgler, J.; 2006; Investor sentiment data; Wurgler's personal webpage; http://pages.stern.nyu.edu/ jwurgler/main.htm 


\section{References}

Asness, C.S., Moskowitz, T.J., Pedersen, L.H., 2013. Value and momentum everywhere. Journal of Finance 68, 929-984.

Baker, M., Wurgler, J., 2006. Investor sentiment and the cross-section of stock returns. Journal of Finance $61,1645-1680$.

Barroso, P., Santa-Clara, P., 2015. Momentum has its moments. Journal of Financial Economics 116, 111-120.

Belousova, J., Dorfleitner, G., 2012. On the diversification benefits of commodities from the perspective of euro investors. Journal of Banking and Finance 36, 2455-2472.

Blitz, D., Huij, J., Martens, M., 2011. Residual momentum. Journal of Empirical Finance 18, 506-521.

Bodie, Z., Rosansky, V.I., 1980. Risk and return in commodity futures. Financial Analysts Journal 36, 27-39.

Carhart, M.M., 1997. On persistence in mutual fund performance. Journal of Finance 52, 57-82.

Chordia, T., Shivakumar, L., 2002. Momentum, business cycle, and time-varying expected returns. Journal of Finance 57, 985-1019.

Conover, C.M., Jensen, G.R.., Johnson, R.R., Mercer, J.M., 2010. Is now the time to add commodities to your portfolio? Journal of Investing 19, 10-19.

Cooper, M.J., Gutierrez, R.C., Hameed, A., 2004. Market states and momentum. Journal of Finance 59, $1345-1365$.

Daniel, K., Jagannathan, R., Kim, S., 2012. Tail risk momentum strategy returns. Working paper, NBER.

Daniel, K., Moskowitz, T.J., 2016. Momentum crashes. Journal of Financial Economics 122, 221-247.

Daskalaki, C., Skiadopoulos, G., 2011. Should investors include commodities in their portfolios after all? New evidence. Journal of Banking and Finance 35, 2606-2626.

D’Avolio, G., 2002. The market for borrowing stock. Journal of Financial Economics 66, 271-306. 
Engleberg, J.E., Reed, A.V., Ringgenberg, M.C., 2018. Short-selling risk, Journal of Finance 73, 755-786.

Erb, C., Harvey, C., 2006. The strategic and tactical value of commodity futures. Financial Analyst Journal 62, 69-97.

Fama, E.F., French, K.R., 1987. Commodity futures prices: Some evidence on forecast power, premiums, and the theory of storage. Journal of Business 60, 55-73.

Fama, E.F., French, K.R., 1993. Common risk factors in the returns on stocks and bonds. Journal of Financial Economics 33, 3-56.

Fama, E.F., French, K.R., 2015. A five-factor asset pricing model. Journal of Financial Economics 116, $1-22$.

Fama, E.F., French, K.R., 2018. Choosing factors. Journal of Financial Economics 128, 234-252.

Gorton, G., Hayashi, F., Rouwenhorst, K., 2012. The fundamentals of commodity futures returns. Review of Finance 17, 35-105.

Grundy, B., Martin, J.S., 2001. Understanding the nature of the risks and the source of the rewards to momentum investing. Review of Financial Studies 14, 29-78.

Hakansson, N., Ziemba, W., 1995. Capital growth theory. In: Jarrow, R., Maskimovic, V., Ziemba, W. (Eds.), Handbooks in Operations Research and Management Science. North-Holland, Amsterdam.

Hansen, L.P., Jagannathan, R., 1997. Assessing specification errors in stochastic discount factor models. Journal of Finance 52, 557-590.

Jegadeesh, N., Titman, S., 1993. Returns to buying winners and selling losers: Implications for stock market efficiency. Journal of Finance 48, 65-91.

Jensen, G.R., Johnson, R.R., Mercer, J.M., 2000. Efficient use of commodity futures in diversified portfolios. Journal of Futures Markets 20, 489-506.

Kang, J., Kwon, K.Y., 2017. Momentum in international commodity futures markets. Journal of Futures Markets 37, 803-835. 
Lesmond, D.A., Schill, M.J., Zhou, C., 2004. The illusory nature of momentum profits. Journal of Financial Economics 71, 349-380.

Long, J., 1990. The numeraire portfolio. Journal of Financial Economics 26, 29-69.

Lutzenberger, F.T., 2014. The predictability of aggregate returns on commodity futures. Review of Financial Economics 23, 120-130.

Lutzenberger, F.T., Gleich, B., Mayer, H.G., Stepanek, C., Rathgeber, A.W., 2017. Metals: Resources of financial assets? A multivariate cross-sectional analysis. Empirical Economics 53, 927-958.

Maio, P., Santa-Clara, P., 2012. Multifactor models and their consistency with the ICAPM, Journal of Financial Economics 106, 586-613.

Miffre, J., Rallis, G., 2007. Momentum strategies in commodity futures markets. Journal of Banking and Finance 31, 1863-1886.

Pirrong, C., 2005. Momentum in futures markets. Working paper, University of Houston.

Ross, S.A., 1978. A simple approach to the valuation of risky streams. Journal of Business 51, 453-476.

Shen, Q., Szakmary, A.C., Sharma, S.C., 2007. An examination of momentum strategies in commodity futures markets. Journal of Futures Markets 27, 227-256.

Stambaugh, R.F., Yu, J., Yuan, Y., 2012. The short of it: Investor sentiment and anomalies. Journal of Financial Economics 104, 288-302.

Szymanowska, M., de Roon, R., Nijman, T., Goorbergh, R., 2014. An anatomy of commodity futures risk premia. Journal of Finance 69, 453-482. 